\title{
A TRADIÇÃO NA EXPERIÊNCIA FILOSÓFICA NIETZSCHIANA
}

\section{Lúcia Schneider Hardt ${ }^{*}$}

Resumo: O texto tem como propósito realizar uma reflexão sobre a ideia da tradição, considerando a experiência nietzschiana. A tradição não é o oposto da contemporaneidade, não impede a reflexão sobre o presente. A tradição, em qualquer perspectiva filosófica bem como em qualquer dimensão cultural, é um recurso utilizado para explicar nossa inserção na história, poderá ser um recurso para reeditar esta inserção considerando os desafios atuais.

Palauras-chave: Tradição. Educação. Formação. Moral. Nietzsche.

Resumen: El texto tiene como objetivo desarrollar una reflexión sobre la idea de considerar la experiencia de la tradición nietzscheana. La tradición no es lo contrario de la actual, no impide la reflexión sobre el presente. La tradición, en cualquier punto de vista filosófico, así como a cualquier dimensión cultural, una función que se utiliza para explicar nuestra inserción en la historia, como pueden ser un recurso para volver a emitir esta inserción de los actuales retos.

Palabras claves: Tradición. Educación. Formación. Moral. Nietzsche.

Filosofia e tradição são temas controversos. Um parece depender do

\footnotetext{
"Professora da Universidade Federal de Santa Catarina. E-mail: luciashardt@gmail.com.
}

outro, contudo, a análise do assunto merece atenção especial. Particularmente em Nietzsche, o assunto é polêmico e ambíguo. De imediato pode dar a impressão que o filósofo, ao realizar sua crítica à modernidade, está despedaçando toda a tradição $e$ que seria exatamente isto que o destacaria como um pensador irreverente. Ele enfrenta determinada tradição e afirma outra.

Nestes termos o texto pretende destacar a reflexão praticada junto a alunos da graduação em curso de formação de professores e na disciplina de Filosofia da Educação para exatamente lidar com esta ambiguidade entre tradição e filosofia. Os alunos, em geral, apreciam os textos nietzschianos pela sua intempestividade, ironia, crítica, acidez. Parece uma aderência imediata àquilo que se mostra supostamente "revolucionário". Contudo, na sequência dos estudos, vão estranhando a crítica quando ela se dirige tão intensamente sobre o tema da moral. Afinal, o que 
pretende este pensador ao solapar nossa confiança na moral e nos valores? Do entusiasmo inicial, tem início uma rejeição.

Tomar um autor para pensar com ele significa outra coisa que virar discípulo. A graduação parece ser este espaço para refletir sobre alguns pensadores, sem de imediato desejar que os alunos decidam aderir ou julgar. Este foi o prosseguimento do desafio docente, superar a ideia de excesso de entusiasmo e também de rejeição para conhecer de fato a obra $e$, na maioria dos casos, partes e segmentos da produção do filósofo. O eixo motivador foi iniciado pelo conceito de tradição.

Nos debates em aula partimos do conceito de arte defendido e destacado no Nascimento da tragédia, obra do Nietzsche jovem, que privilegiou Wagner e Schopenhauer, estilos representativos da beleza e da afirmação da vida. Esta foi a expressão da fase nietzschiana considerada a metafísica do artista, pois representava a beleza sem a subordinação à lógica. Os dois modelos pareciam enfrentar, por um lado, a moral e, por outro, a filosofia ocidental. Mais tarde, o pró- prio Nietzsche revisa a obra - Nascimento da tragédia - percebe que se serviu de uma linguagem comum para tentar fazer algo incomum. Teria sido necessária outra linguagem, outras palavras, outra beleza. Na maturidade filosófica já não suportará a resignação presente em Schopenhauer, muito menos a submissão de Wagner ao Estado. Acaba rejeitando os dois modelos enquanto expressão de uma cultura nobre. E não rejeita utilizando-se de argumentos avessos à tradição, mas por reconhecer que a tradição helenística foi desconsiderada pelos dois artistas. Seria necessário escavar mais, caminhar para trás e de novo encontrar-se com a arte do tempo pré-socrático: a tragédia. São esses os itinerários de Nietzsche em busca de uma tradição, de uma afirmação da vida que é trágica e que foi negada.

Nietzsche pensava ter tocado dois belos modelos de arte, mas percebe que precisava percorrer ainda outros caminhos para reencontrar a arte pré-socrática, a musicalidade e tragicidade dionisíaca que quer muito mais da vida que sua suposta negação. Além disto, Nietzsche percebeu 
que também "fabulou" a exemplo dos modernos, quando achou ter visto na manifestação da música alemã uma expressão quase análoga à arte grega. Em seus textos acaba por confessar: "o que via e me encantava, 'era a menos grega de todas as formas possíveis de arte' (2007, p. 19), o que me exigiu outro rumo, sem, contudo abandonar a arte". Afinal, que outra música e outra palavra podem expressar um "jeito trágico de ser"? (SILVA, 2011, p. 107). Que outra estética é possivel, desde que a vida e a natureza possam temperar e fermentar o que por fim aparece?

Nietzsche contesta uma tradição que acredita no livre-arbítrio, na existência das causas finais, na existência de uma realidade transcendente, na perenidade dos valores, no controle da razão. Contesta uma tradição que caiu na armadilha da moral. Retomamos a ambiguidade do termo: Afinal, qual tradição o filósofo destaca? Nos gregos pré-socráticos encontra outra tradição que não é subsumida pela moral e pela obediência, mas pela afirmação da vida.

O enfrentamento da moral em Nietzsche não postula uma rejeição sistemática a esta, mas um desejo de investigar sua proveniência $e$ expor diferentes perspectivas. Seu maior desejo é solapar a confiança na moral $e$, por fim, reconhece que toda moral é, em alguma medida, uma forma de coerção, uma oposição ao "livre curso" da natureza. Deseja um tempo em que valores possam ser escolhidos, designados pela vontade para afirmar possibilidades singulares de existência. Nietzsche questiona a conversão da cultura antiga ao gosto dos mestres da moral. Em Aurora (NIETZSCHE, 2008, p. 138), indaga: Aprendemos algo daquilo que justamente os antigos ensinavam à juventude? Aprendemos a falar como eles, a escrever como eles? Aprendemos a grande arte da conversação? Aprendemos a nos mover com beleza e altivez, a sobressair na luta, no jogo, no pugilato, como eles?

Também sua crítica a Sócrates, questionando sua visão moral de mundo, deseja apontar a mutabilidade dos valores, supostamente negada por Sócrates. Valeria aqui destacar a "ironia" de Parmeggiani (2004, p. 126) quando afirma: 
Os valores e sentidos incondicionados, próprios da visão moral do mundo, não conformam a tradição porque a negam em suas bases existenciais. Ésquilo e Sófocles fundam suas raízes nesse solo-fundo (Boden) da tradição, extraindo dele, como condição a priori, multiplicidades de sentido que por isso mesmo são irredutíveis às dicotomias morais. Pelo contrário, Eurípedes põe em questão e desliga-se petulantemente da tradição helênica, desde um sentimentalismo da moral, em que tudo se resolve no conflito "dramático", no combate entre o Bem e o Mal - ainda que não tenha fim -, em busca de uma razão última - Grund, o grande guia do Bem - capaz de proporcionar um sentido autêntico à nossa existência, separando-nos do fundo múltiplo e caótico que a constitui.

A dimensão estética em Nietzsche é oriunda de uma cosmovisão que em grande medida enfrenta a racionalidade socrática e platônica. Ao invés da racionalidade, a apresentação da arte trágica, o retorno aos instintos apolíneos e dionisíacos como alternativa ao pensar racional. Em seu primeiro livro, o Nascimento da tragédia, a arte é um imenso contexto de onde tudo nasce. O herói trágico ensina a viver em tempos gregos $e$ assim cultura e formação precisam se debruçar sobre esta condição para compreender o viver pleno. Um viver que depende de dois instintos: apolíneo e dionisíaco. No Nietzsche jovem essas duas medidas parecem acessar um cenário de equilíbrio, contudo, posteriormente, o filósofo vai priorizar a dimensão dionisíaca.

Nietzsche, em seu período "médio", debruça-se sobre a ciência e percebe quão importante é este conteúdo para reconhecer a força artística da vida. A natureza viva pode ser compreendida pela fisiologia, psicologia, química indicando forças que disputam espaços, tempos para afirmar-se. Em síntese, o homem científico acaba também por reconhecer-se como artista.

O livro Aurora inaugura uma discussão sobre o conhecimento e sua relação com a moral. Existe uma tensão nesse ponto. $\mathrm{O}$ conhecimento exige espíritos livres e não obedientes. Não contemplar apenas o que está arrumado, arranjado para nos seduzir. Probidade intelectual implica duvidar do que está arranjado e até mesmo do que se possa arranjar para colocar neste lugar. A confrontação de Nietzsche com a moral, especialmente com o cristianismo, é uma questão em torno do tanto de força $e$ tensão que suportamos ao pensar. A ciência vem como parceira desse desafio, como nova ferramenta de luta. 
Seria suficiente pensar que a superação da moral se daria apenas com o nascimento de outra estética da existência? Esta seria a forma de superar a moralidade? Do campo da crítica às práticas educativas: Afinal, o que significaria mesmo inovar, criar no terreno pedagógico? Como produzir outra formação em cursos de graduação para desenvolver nos alunos a vontade de pensar antes de qualquer militância?

Talvez a tarefa educativa mais importante seja cultivar em si mesmo esse outro homem, capaz de suportar as tensões do pensamento para fazer surgir atos singulares, outras auroras pedagógicas. A racionalidade sempre manteve a palavra capturada pelos conceitos. Nietzsche quer se lembrar do canto, da música, da arte, do desejo, da poesia que seduz a palavra para criar outra cena e outro espaço de expressão da vida. Quer seduzir também aquele que deseja aprender, conhecer, tocar o belo. Subordinar a educação apenas ao conceitual parece ter retirado da experiência a beleza da aprendizagem. Antes de qualquer reação já podemos afirmar que não está em questão fazer da educação o campo do irracional, da expulsão da palavra, mas sim a inserção do canto, da música, da arte, da poesia, da literatura. Um canto que, metaforicamente, ergue uma vontade: encantar quem deseja aprender para além da palavra presa ao conceito.

A subordinação do belo ao racional ocorre em função do domínio de determinada moralidade, e de um modelo dado como único e melhor. Na modernidade houve um empenho em fazer do homem um incorporador de hábitos e costumes, adestrando-o a certa ideia de cultura. Dessa convicção consolida-se, inclusive, uma defesa: a formação humana compreende uma assimilação do costume, incorporar a ideia de que é positiva a ideia do hábito de ter hábitos. O hábito converte-se em costume e depois em tradição. No livro Aurora, Nietzsche afirma que a moralidade é obediência a costumes, $e$ a tradição implica autoridade que impõe subordinação. Deixar o indivíduo livre parece um perigo, os espíritos livres não se agrupam de forma desejada, muito menos desejam inserir-se nos modelos existentes. Neste lugar o que seria então a tradição para Nietzsche? 
Uma autoridade superior, a que se obedece, não porque ela manda nos fazer o que é útil, mas porque ela manda. - Em que se distingue esse sentimento pela tradição do sentimento do medo em geral? Ele é o medo diante do intelecto superior que manda, diante de uma potência inconcebível, indeterminada, diante de algo mais que pessoas - há superstição nesse medo. (NIETZSCHE, 2008, p. 19).

A tradição converteu-se em costume para evitar ações individuais. O homem individual é visto como imoral, pois quer depender de si mesmo e não de uma tradição. A dimensão moral do ser humano fica configurada pelo esforço em seguir os costumes, e mais, estabelecer e consolidar um tipo de sociedade e de cultura. E esse tipo de cultura não quer mais permitir outras experiências vivenciadas em outros tempos, pois outra vivência pode resultar em outros costumes. A moralidade que se opõe a que se façam novas experiências para alterar, romper com os costumes embrutece a formação humana.

Em alguma medida, o Nietzsche maduro parece desejar tomar a palavra como arte e como música, o que fica exposto por meio do livro
Zaratustra. Este movimento implica retomar uma tradição, uma experiência vivida no período pré-socrático quando a música tinha mais destaque que o conceito. Retomar a tradição, não significa cair na armadilha do costume e da moralidade, talvez sim, revisitá-la para outra vez enfrentar as tensões do pensamento antes das definições morais dadas como universais.

Assim podemos dizer que inicialmente Nietzsche absolutiza a arte como espaço da formação, para posteriormente empenhar-se em fazer arte com a palavra em movimento. Vejamos a crítica que ele mesmo faz a seu primeiro livro ao perceber na maturidade que enfrentou a racionalidade socrática da forma menos adequada, ou seja, por meio de argumentos e conceitos. Em algum momento afirma: "[...] é pena que eu não me atrevesse a dizer como poeta aquilo que tinha a dizer..." (2007, p. 14).

Aparece outra tradição, outra vivência, outro valor. Em cada escrito do filósofo é preciso entender como ele indica qual a tradição que comba- 
te e qual aquela que quer reencontrar.

Para Nietzsche, é nefasta a atitude de tomar da tradição uma de suas múltiplas formas para fixá-la em função de interesses sectários e conservadores. O fim da tradição não é o ajustamento, a acomodação a valores absolutos, mas ela deseja acréscimo de vida, uma defesa da criatividade humana.

Formar alunos na graduação não significa fixá-los no professor $e$ nas suas convicções, acomodando-os aos projetos de pesquisa já existentes, e tornando-os obedientes para poder existir na instituição. Cultivar nos alunos vontade de expansão de vida, acréscimo de energia implica, contudo, valores outros que insistem em nos capturar.

A capacidade de selecionar em Nietzsche não pode igualmente ser confundida com a intenção totalmente desinteressada de reunir diferenças para convencer ou agradar públicos específicos. Surge um pluralismo, ecletismo, como refere Parmeggiani (2004), que alberga uma suposta criatividade que, em síntese, converte-se em um utilitarismo para controlar $e$ manipular a realidade. "A atitude eclética é um sintoma claro do debilitamento da capacidade criativa no indivíduo. O eclético justapõe, não compõe nem desenvolve, porque se limita a mesclar de maneira engenhosa elementos heterogêneos" (PARMEGGIANI, 2004, p. 129).

Nesses termos o que é então para Nietzsche a escolha, o gosto, o estilo? Nietzsche, em Ecce homo, nos oferece três atitudes que esperaria de seus leitores: a calma - o ler sem pressa, a não intromissão no texto, o não trazer a sua própria formação para o texto - ler simplesmente e não ter expectativas de conclusões. O leitor desejado deve, inicialmente, compreender o gosto daquele que escreve, desejar saber as escolhas que fez, o caminho que percorreu sem interferências. Invadir precocemente este espaço é não ler, é produzir um terreno confuso onde aquele que lê parece querer ser reconhecido. Ler Nietzsche é uma luta contra a universalidade, ele não deseja contemplar a todos, ele quer ser lido por quem deseja compreendê-lo. Vale mesmo também não ser compreendido. Nesses termos, por onde ficaria o espírito livre? 
Está ao lado da probidade intelectual, ou seja, daquele que "sabe ler sem deformar" (PASCHOAL, 2012, p.73) para, depois, por meio de uma prática de independência, sentir-se capaz de também interpretar tal como o próprio autor. Nietzsche não deseja discípulos, pensa em leitores fortes, curiosos - mas jamais apressados - $e$ assim solicita, do leitor, primeiro uma honestidade em relação ao texto que decide conhecer.

E nós, educadores, queremos qual aluno? Como favorecer nos alunos o desenvolvimento do espírito livre, ensinar o ler sem deformar? Reconhecer que o contato com a tradição implica um exercício heurístico, um encontro com problemas que desejam nos fazer pensar e não sossegar nossa curiosidade. Sem pressa, demoradamente.

Pertencemos a uma civilização privada da possibilidade de escolha, a seletividade ficou subsumida por um instinto gregário ou eclético que supostamente nos protege; nesse caso, escolher é aproximar-se do que é mais comum, mais genérico, mais agregador ou em tempos mais recente, mais heterogêneo desejando ser contraditório para parecer inovador e progressista. Sair desta fronteira é perigoso, desviamos do caminho reto e perdemos a identidade. Mas o que é o gosto para Nietzsche? Como aprender sobre isto lendo sobre suas escolhas? Como incentivar o aluno a escolher, a dar forma a seu próprio gosto?

$$
\text { O gosto - Geschmack - está li- }
$$

gado a um instinto de autoconservação, nem tudo podemos incorporar, não podemos desperdiçar nossa energia inadequadamente, por isto é necessário escolher e para escolher é preciso conhecer aquilo que será escolhido. Discernimento, depuração, tempo, separação, recusa, incorporação, por fim habilidades da escolha. A autoconservação implica reconhecer que nem tudo nos faz bem, não podemos simplesmente consumir. $\mathrm{O}$ gosto, no sentido nietzschiano, é também uma forma de dizer não, de rejeitar o que não é importante. Não saber dizer "não" nos torna manipuláveis. O gosto não nos põe diante das solicitações cotidianas como um consumidor de tendências, mas também como alguém que é capaz de distanciar-se, que não desperdiça energia com tudo que lhe é oferecido, 
que desconfia, suspeita para descobrir seu próprio gosto.

A vida exige escolhas e cuidados e a vida que vingou é aquela que exigiu de si mesma muito, aprendeu a guardar e descartar. Somos fecundos enquanto não relaxamos, não nos ajustamos, permanecemos jovens quando não nos contentamos com a paz. Segundo Nietzsche, precisamos estar à altura do inesperado:

Minha humanidade é uma contínua superação de mim mesmo. - Mas tenho necessidade de solidão, quer dizer de recuperação, retorno a mim, respiração de ar livre, leve, alegre... Todo o meu Zaratustra é um ditirambo à solidão, ou, se fui compreendido, à pureza... Felizmente não à pura tolice. (NIETZSCHE, 2008, p. 31).

Para Nietzsche reunir todos os estilos, ou aspectos de cada perspectiva, pode ser grotesco em termos de estilo. Justaposição de temperos estéticos não constitui estilo. Assim, o pluralismo, que não é nietzschiano, não necessariamente é um componente do estilo, do cuidado de si. Ter estilo é ser produtivo, nem sempre significa ser construtivo. Por vezes eliminamos a singularidade de um estilo em função da "tirania de uma cultura real e efetiva" que insiste em se manter. A estratégia tem sido paralisar estilos, justamente os mais poderosos e vigorosos.

Por vezes não estaríamos como educadores paralisando estilos de alunos que resistem aos nossos arranjos pedagógicos e teóricos? Às vezes, a resistência deles não tem ainda toda a força, mas já é um indicador de outra travessia que até já esquecemos e que pode de novo nos fazer pensar a tarefa docente.

A condição da escolha implica coragem, liberdade. Para Parmeggiani (2004, p. 134), "o pluralismo nietzschiano não tem nada a ver com o ecletismo pós-moderno, porque $\mathrm{Ni}$ etzsche o elabora como perspectivismo". Um perspectivismo que assume escolhas, e com isso lutas e embates singulares constituindo um estilo para "tornar-se o que se é" - especialmente abordado em Ecce homo: de como a gente se torna o que a gente é uma lição para toda vida.

Como inventar outro canto $e$ outra linguagem para a educação? A vaidade dos mestres é imaginar que já sabem para qual direção devem encaminhar seus alunos. Diante da 
encruzilhada não titubeiam - preferem obedecer a arriscar. Formação como uma espécie de bem-estar na relação com o caminho, com a direção. Formação como finalidade antecipadamente arranjada.

O outro canto poderá iniciar com uma espécie de Pedagogia da interrupção (BIESTA, 2013), que significa suspender práticas pedagógicas para "ficar a sós" e pensar na formação e na educação cada vez de novo. Todos não são uma boa companhia, destinar todos ao mesmo lugar é fracassar, então tomar cada um como propósito é também uma espécie de solapamento moral da educação. Nesses termos cabe uma indagação: Teríamos nós também esquecido o "jeito trágico de ser", de ser educador?

As instituições não ensinaram ao homem a selecionar, escolher. Educar e disciplinar significou criar uma criatura capaz de fazer promessas e armazenar informações. A tendência é produzir no humano uma máxima: "tu deves", que o levará a cumprir a promessa e se livrar da má consciência. A força que pode agir no sentido contrário chama-se esqueci- mento. Escolher esta habilidade é dar ao organismo a oportunidade de cultivar algo novo e recusar certas promessas e determinadas informações. Segundo Nietzsche, nenhuma felicidade, serenidade, jovialidade e gozo serão possíveis sem a faculdade do esquecimento.

Uma espécie de antídoto inventado pelos moralistas foi a memória. Era preciso controlar o esquecimento em função de interesses coletivos. O desejo de proteção deveria produzir no homem atitudes previsíveis e comprometidas com a coletividade. Mais uma vez reprime-se um instinto, o instinto do esquecimento, que é uma forma de saúde, de força para criar. O homem deve prender-se ao que prometeu, para viver um futuro mais seguro, e o corpo fica pressionado a lembrar; deve rejeitar o que deseja, deve ser amansado.

A memória origina-se em uma violência que toma o corpo para embotar instintos e reafirmar condutas sociais. O corpo útil aprende rápido a quem obedecer; caso contrário, sentese desprotegido e só. Mas a memória também é uma ferramenta para lembrar-se da vontade, da força, do espí- 
rito livre, da capacidade de interrupção. Ativar um espírito livre, capaz de independência e de comando de si. Perde-se a espontaneidade quando se fica acorrentado a regras e promessas. Criar no homem um sentimento de falta, de déficit, de dívida faz o homem ter medo e, ao torná-lo acuado, ele oferece seu corpo a qualquer preço para retomar um suposto bemestar: uma vida calculada, controlada, sem espontaneidade, responsável. A vida passa a ficar ligada ao dever, e a memória desprovida da vontade o lembra do castigo. Já não mais arris$\mathrm{ca}$, aventura-se. Ajustou-se visando à paz, teme o imprevisível, o improvável, a morte. Para suportar este estado de coisas, inventa e cria falsas certezas e coloca sua vida no futuro, sem vivê-la em tempo presente.

A dimensão trágica da educação é a própria dimensão estética, pois compreende a complexidade da vida, reconhece o sofrimento, a turbulência, o inaudito, mas sabe que ele vem da vida que se mostra em abundância e busca na arte uma expressão dessa energia para ser vivida afirmativamente e não silenciada pelos ajustes e convenções sociais.
A invenção que não rejeita a tradição, mas talvez possa, de fato, escavar o terreno para aquilo que acabou sendo dispensado exatamente por ser dito como tradicional. Voltar a pensar sobre o conceito de arete, que não é do tamanho de uma receita pedagógica, mas implica a coragem de um sujeito que reconhece de novo sua "vulcanidade" (SILVA, 2011, p. $115)$ instintiva para criar. A mais elevada arete é aquela que é capaz de "fazer sua a beleza" (JAEGER, 2001, p. 35). Para os gregos, aspirar à beleza significa não desperdiçar energia, mas concentrá-la no que de melhor poderá surgir de nós mesmos. Esta força apresenta-se de uma forma rara e singular. O espírito de guerra, a destreza do uso das ferramentas e das armas exige perseverança e coragem. Infelizmente, nossas guerras estão sendo delineadas unicamente pelas demandas coletivas, que ficam legitimadas, pois representam a maioria. A maioria não é condição suficiente para produzir beleza, existe algo de singular na beleza e que não pode ficar minimizada em função de sua pouca liquidez quantitativa. 
A estética de Nietzsche nasce da vida, está baseada na afirmação de que a vida pode nos satisfazer pela sua própria condição. Esta ideia vem da tradição grega, mas certamente existe em outras culturas com outros formatos. Importa conhecer e estudar a vida em determinados momentos históricos e culturais. Para existir uma reflexão nova sobre a vida, será preciso outro estilo, outra linguagem, outra experiência. Assim, o estético em Nietzsche jamais significará seguir os parâmetros do belo, da sensibilidade, do arranjo inventado para impressionar. O estético nasce de uma força, de uma vontade de potência que deseja afirmar a vida para reinventá-la sempre que necessário.

Quando criticou "o jeito racional de ser" (SILVA, 2011, p. 107) em Sócrates no Nascimento da tragédia, Nietzsche, segundo Machado (1994, p. 140), produz uma crítica da morte do trágico pelo saber racional, da lógica e do argumento. Assim: "Que validade poderá ter uma crítica da razão feita a partir da razão?" (MACHADO, 1994, p. 140).

O que fica exposto desse modo é que a tragédia não pertence ao mundo do racional. Nem por isso pode ser definida como irracional. Segundo Machado, inspirado por Nietzsche, está em questão pensar outra filosofia que reivindica uma postura trágica, dionisíaca e que, portanto, ao reeditar a tradição

precisa se expressar numa linguagem adequada a essa visão de mundo: uma linguagem artística e não científica figurada e não conceitual. Ora, se essa dificuldade não parece, aos olhos de Nietzsche, intransponível, isto se deve, principalmente, ao livro que, um ano antes, ele havia concluído e que ele destaca como a parte de sua filosofia que diz sim: Assim falou Zaratustra. Não é, a esse respeito, sintomático que a "tentativa de autocrítica" se encerre com um trecho desse livro, sobre a alegria trágica, logo depois de Zaratustra, a personagem central, ser chamado de "demônio dionisíaco"? Minha hipótese é que Assim falou Zaratustra é o canto que, em 1886, Nietzsche lamentou não ter cantado com seu primeiro livro, significando sua tentativa mais radical de evitar a contradição da luta contra a razão se realizar através de uma forma de pensamento submetido à razão. (MACHADO, 1994, p. 140).

Desse lugar, dessa definição de estética, dessa experiência de linguagem e de canto desejo tecer outros fios e outra trama: a possibilidade estética da experiência docente. Nietzsche produz outra filosofia, cria linguagem e musicalidade no texto, 
recusa e enfrenta a metafísica, encontra-se, parece, com a bela forma grega (expressão de uma tradição) tão desejada desde o início do seu filosofar. E nós, educadores, o que mesmo desejamos, o que recusamos e o que somos capazes de inventar?

Certamente não caberia tomar Nietzsche como modelo, mas colocarse ao lado para continuar pensando com ele e com suas ferramentas que ainda hoje parecem ter função. Como diz Silva (2011), nosso mundo pedagógico é excessivamente otimista e ajustado ao império das vontades políticas. O jeito racional de ser em termos educacionais sempre produziu mais aderência que recusa, mais ajuste que invenção, mais resignação que duelo.

Para Nietzsche, a capacidade de recusa implica duelo, luta, embate, força, jamais resignação. O contexto da formação do herói grego ocorre na arena pública, e quando Nietzsche recusa a democracia quer trazer de volta uma concepção política própria dos gregos. Assim, a aristocracia do filósofo está ancorada em grandes feitos destes heróis, acima do bem e do mal. A política a serviço da moral degenera também a serviço de preocupações econômicas. O valor da política, da grande política é dar destaque a grandes homens capazes de conduzir ações criativas e corajosas. A liberdade, no âmbito do agon grego, está ligada a grandes e criativas ações, não devem ser avaliadas por um julgamento moral, e sim pela excelência contida em seu desempenho.

Já os herdeiros da Aufklärung não podem entender esta posição do filósofo que entendia que o maior desafio do ser humano é colocar para si mesmo o mais elevado valor, independente da moral e dos costumes. Mais importante seria viver servindo os homens mais raros, mais elevados, $e$ não atender aos interesses da maioria ou de um sistema que tudo explica e normatiza. Este homem poderia ser aquele que chamou de espírito livre, além-homem, o indivíduo soberano. Para que esse homem surja é preciso restabelecer a dimensão trágica da filosofia, que é, em certa medida, a tradição que Nietzsche quis resgatar. O trágico é anfitrião tanto da criação quanto da destruição, consegue compreender o que é sombrio e o que é luminoso. Faz filosofia por nuances, 
reconhece a fluidez dos sentidos. Rejeita uma visão otimista da vida e não deseja uma vida conformada, sempre compreensível, restrita a segurança, conforto e bem-estar. A dimensão trágica não elimina a racionalidade da vida, apenas não permite a sua tirania. Não podemos tudo corrigir, salvar, arrumar, desvendar, descobrir, a vida também implica saber levar seu lado sombrio e por vezes doloroso.

Assim, a tradição na filosofia de Nietzsche tem lugar, mas a tradição resgatada pela afirmação da vida, a vontade de poder. A ideia de tradição implica uma ideia de passado, memória, história. Nietzsche desaprova a busca desses elementos para despertar os mortos, enaltecer personagens e momentos históricos. $\mathrm{O}$ tempo deve ser enfrentado para dar lugar a outros tempos, a outros feitos. A extemporaneidade é uma forma de lidar com o presente e o passado, não para acumular e destacar pessoas $e$ fatos, mas para pensar o que ainda está por vir. Repetir os gregos não significa repetir a ação, mas a capacidade de ser afirmativo diante da vida e com esta força continuar pensando seu tempo e contra seu tempo. E essa reflexão exige o indivíduo forte, corajoso, criativo, capaz de ser original. Nietzsche diferencia-se dos românti$\cos$ que, ao buscarem o passado, querem ser como os gregos, atitude que esteve presente em parte no $\mathrm{Ni}$ etzsche jovem. Contudo, o filósofo acaba por compreender que é na extemporaneidade que está a leveza da criação e o desafio de cada homem em função do seu tempo.

Com isso, a forma como $\mathrm{Ni}-$ etzsche toma o passado é diferente dos românticos, não quer repetir, enaltecer as formas belas, adaptar-se aos modelos conhecidos. $\mathrm{O}$ que $\mathrm{Ni}$ etzsche aprende com os clássicos é o valor da ação. Não basta contemplar os grandes dramas humanos, o valor está em tomá-los como temas da vida para afirmar-se criativamente. Os temas do romantismo sugerem uma contemplação que acaba sendo uma espécie de submissão ao já vivido. Segundo Nasser (2011, p. 32) e seguindo as críticas de Nietzsche, os românticos são incapazes de dominar as paixões. O que devemos é atingir a espiritualidade da paixão, não reagir de imediato aos estímulos, valorar o sossego, a lentidão para continuar 
pensando sobre os grandes dramas humanos que sempre estarão entre nós.

Este texto pretendeu mostrar que Nietzsche não é um destruidor das tradições, um irracionalista capaz de tudo desprezar. Pelo contrário, em sua trajetória mostrou o valor das nuances, dos detalhes de uma tradição capaz de provocar "eternamente" deslocamentos, movimentos e pensares humanos para ser interpretada à luz de critérios tocados pela vida, uma vida que deseja tornar-se afirmativa, singular e criativa. Não seriam estes também os desafios de um educador? Ser capaz de perceber nuances, detalhes para criar seu próprio estilo de ensinar, aprender e conviver? Inserir a dor e o prazer implicados pela vida para não reagir simplesmente, mas com vagar e paciência dar uma plasticidade estética ao processo de formação humana?

No Zaratustra de Nietzsche (2007, p. 111) fica exposta uma afirmação importante para a educação: "Retribuise mal um mestre quando se permanece sempre discípulo". Inserir tal princípio à prática docente significa dar à pedagogia um estilo liberto da militância, para fazer nascer nos alunos devires-múltiplos gestados pelo encontro com a tradição, que por meio da escolha, do gosto de cada um demarcarão cartografias formativas mais intensas e singulares. Novo encontro com a formação, sem pressa. Demoradamente.

\section{REFERÊNCIAS}

BIESTA, G. Para além da aprendizagem: educação democrática para um futuro humano. Belo Horizonte: Autêntica, 2013. (Coleção Educação: Experiência e Sentido).

JAEGER, Werner. A formação do homem grego. 3. ed. São Paulo: Martins Fontes, 1995.

JULIÃO, J. N. Considerações sobre o aristocrático e o estado em Nietzsche. Revista Ethica, Rio de Janeiro, v. 9, n. 1 e 2, p. 109-118, 2002.

GIACÓIA JR., Oswaldo. Nietzsche. São Paulo: Publifolha, 2000. 
MACHADO, Roberto. Arte e filosofia no "Zaratustra" de Nietzsche. In: NOVAES, Adauto (org.). Artepensamento. São Paulo: Companhia das Letras, 1994.

NASSER. Eduardo. "O Romantismo em Nietzsche enquanto um problema temporal, estético e ético". In: As ilusões do eu Spinoza e Nietzsche. MARTINS, A.; SANTIAGO, H.; OLIVA, L. C. Rio de Janeiro: Civilização Brasileira, 2011.

NIETZSCHE, Friedrich. Crepúsculo dos ídolos ou como se filosofa com o martelo. São Paulo: Companhia das Letras, 2006.

Assim falava Zaratustra. Um livro para todos e para ninguém. Petrópolis, RJ: Vozes, 2007.

Ecce homo. Porto Alegre: LP\&M, 2007.

PARMEGGIANI, M. Nietzsche: pluralismo e a pós-modernidade. Cadernos Nietzsche, São Paulo, n. 16, p. 121-140, 2004.

PASCHOAL, Antonio Edmilson. A arte de ler nuances. In: AZEREDO, V. D.; SILVA JÚNIOR, I. (orgs.). Nietzsche e a interpretação. Curitiba; São Paulo: Humanitas, 2012. (Coleção Nietzsche em perspectiva, v. I).

RICCI, Ana Paula. Escolha e seletividade em Nietzsche. Dissertação (mestrado) em Filosofia, Universidade São Judas Tadeu, São Paulo, 2007.

SANTANA, Leila Navarro. Memória: construção sangrenta. Morpheus revista eletrônica. Publicação on-line semestral - ISSN-16 762924.

SILVA, Sérgio Pereira da. Pedagogia do ressentimento: o otimismo nas concepções e nas práticas de ensino. Revista Brasileira de Estudos Pedagógicos, Brasilia, v. 92, n. 230, p. 107-125, jan./abr. 2011.

VIESENTEINER, Jorge Luiz. O projeto crítico de inversão da compreensibilidade em Nietzsche. In: AZEREDO, V.; SILVA, I. (orgs.). Nietzsche e a interpretação. São Paulo: Humanitas, 2012.

Recebido em 27/08/2013

Aprovado em 19/05/2014 